\title{
Análise de necessidades com base em gênero para orientar a produção de material didático em espanhol: gêneros profissionais do ramo imobiliário ${ }^{1}$
}

\section{Genre-Based Needs Analysis to Guide the Production of Didactic Materials in Spanish: Professional Genres of Real Estate Brokers}

Natalia Labella-Sánchez*

Instituto Federal de Educação, Ciência e Tecnologia do Rio Grande do Sul Porto Alegre - Rio Grande do Sul / Brasil

RESUMO: Considerando que a análise de necessidades é fundamental para estruturar o ensino de línguas para fins específicos e para identificar os conteúdos a serem ensinados (DUDLEY-EVANS; ST. JOHN, 1998; RAMOS et al, 2004), este artigo objetiva trazer algumas reflexôes teórico-metodológicas a respeito de uma análise de necessidades com base em gêneros de texto. Para isso, utilizamos a proposta de análise do sistema de atividades de Bazerman (2005). O resultado de tal análise permitiu identificar os conjuntos de gênero que caracterizam o contexto laboral dos profissionais do ramo imobiliário e propiciou subsídios para direcionar uma futura elaboração de material didático em torno a gêneros, já que os dados revelaram quais gêneros de texto precisam ser utilizados em espanhol pelos corretores e em quais situaçôes comunicativas isso ocorre dentro do sistema de atividade.

PALAVRAS-CHAVE: análise de necessidades, material didático, gêneros profissionais, espanhol, ramo imobiliário.

ABSTRACT: Considering that the needs analysis phase is essential in structuring Spanish language teaching for specific purposes and in identifying relevant material to be taught (DUDLEY-EVANS; ST. JOHN, 1998; RAMOS et al., 2004), this

* natalia.labella@yahoo.com.br

${ }^{1}$ Este artigo é um recorte de minha pesquisa de doutorado (em andamento) realizada no Programa de Pós-Graduação em Linguística Aplicada da Universidade do Vale do Rio dos Sinos (Unisinos), sob a orientação da Profa. Dra. Ana Maria Stahl Zilles e coorientação da Profa. Dra. Vera Lúcia Lopes Cristovão (Universidade Estadual de Londrina). Essa pesquisa está sendo realizada com o apoio e financiamento da Bolsa Pe. Milton Valente (Unisinos). 
article aims to offer some theoretical and methodological discussions and results concerning a genre-based needs analysis of texts from the real-estate broker's market. For this, we used the proposal for the analysis of activity systems, as defined by Bazerman (2005). The results from this analysis made it possible to identify the sets of genres which characterize the work context of real estate professionals, and produced a good grounding to guide the future preparation of genre-based didactic materials, given that the obtained data revealed which textual genres in Spanish were needed by these professionals and in which communication contexts of the professionals' activity system these genres emerge.

KEYWORDS: needs analysis, didactic material, professional genre, Spanish, real estate business.

\section{Introdução}

A forte expansão dos cursos técnicos federais na educação brasileira, com a criação dos Institutos Federais (Lei 11.892/2008), trouxe à tona a necessidade crescente de pesquisas sobre o Ensino de Línguas para Fins Específicos (ELFE), mais precisamente, neste trabalho, para o ensino da língua espanhola.

No Brasil, o ELFE sempre teve presença mais marcante nos cursos de nível superior das universidades (ensino de leitura e/ou escrita de gêneros acadêmicos) ou para segmentos profissionais específicos (negócios ou turismo, por exemplo). Com o crescimento exponencial de cursos técnicos federais para os mais variados níveis educativos, ${ }^{2}$ notamos uma ampliação da necessidade de ofertar um ensino de línguas que atenda aos preceitos da formação geral e cidadã, sem deixar de lado uma formação mais voltada para o mundo do trabalho (BRASIL, 2008).

A oferta de cursos técnicos nos Institutos Federais é bastante variada, principalmente no segmento dos cursos subsequentes. ${ }^{3}$ Muitas vezes, não há material didático disponível em língua espanhola para atender às necessidades

\footnotetext{
${ }^{2}$ Os Institutos Federais foram criados para oferecer formação técnica para estudantes em nível médio (ensino médio integrado, ensino médio concomitante, educação de jovens e adultos na modalidade PROEJA, cursos subsequentes), em nível superior (tecnólogos, licenciatura e bacharelado) e em nível de pós-graduação (especializações e mestrados profissionalizantes).

${ }^{3}$ Os cursos subsequentes são cursos técnicos com duração de 2 a 3 semestres e destinamse a estudantes que já concluíram o ensino médio. Para conhecer os cursos que podem ser ofertados pelos Institutos Federais em nível técnico, consulte o Catálogo Nacional de Cursos Técnicos (BRASIL, 2012). Disponível em: <http://portal.mec.gov.br/index. php?option=com_content\&id=12503\&Itemid=841>. Acesso em: 12 jan. 2013.
} 
dos estudantes e às características dos cursos, caso também do Técnico em Transações Imobiliárias (TTI). É responsabilidade do professor de línguas a elaboração de ementas e materiais didáticos para as finalidades específicas, não só de um curso em TTI, mas também dos demais cursos técnicos no qual o docente atua. A falta de materiais para fins específicos parece ser mais intensa quando nos referimos ao ensino da língua espanhola, já que a longa tradição do ELFE no Brasil pautou-se fortemente no ensino de língua inglesa, em especial, para o ensino da leitura em contexto acadêmico.

Para o sucesso do ELFE, duas etapas são centrais: (1) a realização da análise de necessidades e, com base em seu resultado, (2) a produção do material didático. Quando a proposta é de um ELFE com base em gêneros de texto, entendemos que o trabalho desenvolvido nessas duas fases deve ser bastante articulado. Embora ambas as etapas sejam importantes, o foco do presente artigo é, mais especificamente, refletir sobre uma análise de necessidades que possibilite a identificação dos gêneros de textos, em língua espanhola, relevantes para o desenvolvimento do trabalho dos futuros profissionais do curso Técnico em Transações Imobiliárias, na modalidade subsequente, ofertado por um dos campi do Instituto Federal do Rio Grande do Sul.

O curso de TTI tem como objetivo formar corretores ou assessores imobiliários para atuar em imobiliárias, empresas, incorporadoras e construtoras. Entre as funções que se espera desses profissionais estão: fazer a intermediação na compra, venda, permuta, locação e administração em geral; opinar em matéria de comercialização imobiliária de imóveis como perito; atuar como administrador, mandatário e mediador com a oportunidade de ser figura central nas incorporações e loteamentos. O curso completo tem duração total de três semestres, sendo que a língua espanhola compõe as disciplinas do segundo semestre, com carga horária de 72 horas ( 4 horas/semanais).

Para subsidiar tal etapa, baseamo-nos na proposta de Bazerman (2005) de análise de sistema de atividade (composto pelos conjuntos de gêneros que constituem, por sua vez, o sistema de gêneros), por compreender que seus pressupostos teórico-metodológicos são relevantes para (1) identificar, de forma contextualizada, os gêneros que constituem o contexto profissional de um assessor imobiliário, e (2) observar a forma como esses gêneros se relacionam entre si em tal sistema. Além disso, o resultado de tal análise permite ao professor/pesquisador selecionar os gêneros que podem compor o seu material didático, bem como estabelecer mais facilmente os conteúdos que devem ser trabalhados em sala de aula em função das características de cada gênero de texto. 
Apesar de não nos aprofundarmos, neste artigo, na etapa de organização e de produção do material didático, achamos relevante mencionar que compreendemos que os dados advindos da análise do sistema de atividades (identificação dos gêneros característicos do contexto laboral sob análise e a interrelação entre eles) trazem importantes subsídios para uma futura didatização das características dos gêneros, dentro do quadro do interacionismo sociodiscursivo (ISD), já que o uso da língua permite agir em diferentes contextos, sempre por meio de algum gênero textual adequado à situação de comunicação na qual se encontra o agente (BRONCKART, 2003; 2006; CRISTOVÃO, 2009). Nesse construto teórico, os gêneros são compreendidos como um megainstrumento para o ensino de línguas (SCHNEUWLY, 2004, p. 28), o que possibilita organizar uma proposta de ensino-aprendizagem com base em sequências didáticas que contemplem as características constituintes de cada gênero e promova o desenvolvimento das capacidades de linguagem necessárias para a sua produção efetiva (DOLZ; SCHNEUWLY, 1998; 2004). ${ }^{4}$

Assim, voltando ao cerne deste artigo, ou seja, à reflexão sobre uma análise de necessidades voltada para o levantamento de gêneros característicos do contexto laboral dos profissionais do ramo imobiliário, a fundamentação teórica apresentará (a) as principais pesquisas de ELFE com base em gêneros, dando destaque às pesquisas brasileiras; (b) as características da análise de necessidades para a elaboração de um material didático ou curso; (c) as possibilidades teórico-metodológicas, com base na análise do sistema de atividades proposta por Bazerman (2005), para realizar uma análise de necessidades direcionada ao levantamento dos gêneros de texto presentes

\footnotetext{
${ }^{4}$ Essa proposta de didatização de gêneros no contexto da educação básica brasileira é chamada por Bawarshi e Reiff (2013) de modelo didático brasileiro para ensino dos gêneros. Para os autores, esse modelo compartilha características do modelo dos estudos retóricos de gêneros, do qual Bazerman faz parte, pois ambos "promovem múltiplos e sobrepostos que desenvolvem habilidades cognitivas relacionadas com a consciência de gênero, ensinam a aquisição de estratégias linguísticas ou textuais e mostram como o conhecimento cognitivo e textual de gêneros é moldado pelo contexto sociocultural". (BAWARSHI; REIFF, 2013, p. 225). Cabe destacar, também, que não há no quadro do ISD uma proposta de levantamento de necessidades que permita definir os gêneros a serem ensinados nas sequências didáticas. Assim, entendemos que essa lacuna pode ser solucionada por meio da análise do sistema de atividades proposto por Bazerman (2005).
} 
no contexto laboral desses futuros profissionais. Na sequência, apresentaremos os procedimentos metodológicos utilizados para realizar uma análise de necessidades focada nos gêneros de texto que fazem parte do trabalho do corretor imobiliário. Na discussão dos resultados, apresentaremos os gêneros de texto revelados por esse levantamento (realizado por meio de entrevistas semiestruturadas), em especial os que são utilizados em língua espanhola no contexto imobiliário, e refletiremos sobre algumas diretrizes iniciais que podem direcionar a organização e elaboração do material didático. Por fim, teceremos algumas considerações finais.

\section{Fundamentação teórica}

\subsection{Ensino de línguas para fins específicos com base em gêneros de texto}

Como apontado anteriormente, entendemos que as premissas do ensino de línguas para fins específicos adaptam-se bem à realidade didática dos cursos subsequentes: (a) o ensino da língua estrangeira ocorre em cursos de curta duração e reduzida carga horária; (b) o professor assume o papel de pesquisador, designer, avaliador de material didático, responsável por procurar, selecionar, adaptar e ajustar materiais para as condições e objetivos das aulas (RAMOS, 2005, p.114).

As pesquisas relativas ao ELFE pautadas na análise das características de gêneros ocorrem, no exterior, desde finais dos anos 1980 e início da década de 1990. Entre elas, estão as pesquisas de Martin (1985/1989, 1992, 2000), ${ }^{5}$ de Bazerman (1988, 1994), deBhatia (1993) eas deSwales (1990). Emespecial, aspesquisas e pressupostos teóricos de Swales inspiraram, segundo Heimas e Biasi-Rodrigues (2005, p.122), diversos trabalhos tanto no Brasil quanto no exterior. ${ }^{6}$

\footnotetext{
5 São pesquisas de natureza sistêmico-funcional da Escola de Sydney, voltadas para o ensino de língua inglesa em diferentes contextos.

${ }^{6}$ Entre as pesquisas brasileiras citadas pelas autoras estão: Motta-Roth (1995) e Araújo (1996): resenhas de livros; Aranha (1996): introduçóes de artigos de pesquisa; Santos (1995) e Motta-Roth; Hendges (1996): resumos de artigos de pesquisa; Biasi-Rodrigues (1998): resumos de dissertação; Bernardino (2000): depoimentos de alcoólicos anônimos; Hendges (2001): seções de revisão da literatura; Bezerra (2001): resenhas acadêmicas.
} 
Também interessada em trazer contribuições para o ensino de inglês para fins específicos com base em gêneros no Brasil, Ramos (2004, p.109) aponta a importância de realizar propostas pedagógicas para a sua implementação em sala de aula, “já que pouco ainda foi feito no contexto brasileiro na área de planejamento de cursos baseado em gêneros, principalmente na área de línguas estrangeiras”. Nesse artigo, a autora apresenta uma proposta específica de utilização de gêneros textuais em um curso de inglês para fins específicos e cita outros trabalhos de ELFE no Brasil, envolvendo a utilização de gêneros de texto, tais como o de Staa (2003), voltado para o desenvolvimento de um curso de redaçãao acadêmica, e o de Vian Jr. (2003), cujo resultado foi a elaboração de um curso voltado para o ensino de reuniōes de negócios no contexto bancário. Também podemos somar a esta lista os trabalhos de Ramos et al. (2004), Vian Jr. (2006), Souza (2009), entre outros.

Efetivamente, identifica-se um interesse cada vez maior por pesquisas que tratem do ensino de línguas para fins específicos baseados em gênero, seja para elaborar material didático sobre um gênero específico, seja para realizar uma análise de necessidades buscando identificar os gêneros mais comuns em certos contextos acadêmicos ou laborais.

Da mesma forma, encontramos diferentes pesquisas destinadas ao ensino de espanhol para fins específicos como as de Carrelas (2003), Gregolin (2005), Freitas (2005), Galván (2005), Silva (2008) e Silva (2009). Contudo, diferentemente do que é observado no ensino de língua inglesa para fins específicos, não é comum as pesquisas de espanhol dessa área focarem no ensino com base em gêneros de texto. Dentre as recém-apresentadas, por exemplo, as que se centraram na questão dos gêneros textuais foram as pesquisas de Freitas (2005) e de Silva (2008). A primeira teve como objetivo verificar e caracterizar as atividades de agentes de viagem em situações de trabalho, a partir do conceito bakhtiniano de gêneros, direcionando o ensino de espanhol para as competências escritas e leitoras necessárias naquele contexto laboral. A segunda apresentou uma proposta de organização de material didático de língua espanhola, com a inclusão de diferentes gêneros de texto voltados para a área da saúde.

Assim, observamos que há uma importante tradição no ensino de línguas para fins específicos em torno de gênero de textos, com extensas e importantes pesquisas a respeito (em especial, no exterior), embora, em língua espanhola, isso ocorra em menor proporção.

Nas duas próximas seções, trataremos da etapa de análise de necessidades, fundamental para qualquer proposta em ELFE. Além de destacar as 
características da análise de necessidades no próximo item, na seção 2.3, apresentaremos as vantagens de analisar um sistema de atividades para identificar gêneros característicos de um contexto profissional.

\subsection{Algumas características da análise de necessidades entre as décadas de 1980 e 2000}

Como as necessidades de uso da língua variam muito de acordo com cada contexto, outro ponto importante do ELFE é a questão da análise de necessidades, etapa fundamental para desenhar o curso e organizar os conteúdos a serem ensinados. Baseada em Hutchinson e Waters (1987) e em Dudley-Evans e St. John (1998), Ramos (2005, p.112-113) destaca que a análise de necessidades: 1. pode pautar-se na situação na qual o aluno vai atuar (situação-alvo) e/ou na necessidade do aluno como aprendiz; 2. é fundamental no planejamento de um curso e na definição de quais tarefas específicas o aluno irá desempenhar (e em quais contextos específicos); 3. propicia a seleção adequada de temas e conteúdos relacionados às áreas de atuação do aluno (acadêmicas ou profissionais).

Para aprofundar um pouco mais a importância e as características da análise de necessidades, apresentaremos um quadro elaborado com base em parte da pesquisa de Souza (2009, p.15-20).

\section{QUADRO 1}

Características e objetivos da análise de necessidades para o ensino de línguas para fins específicos, segundo estudos de Souza (2009)

\begin{tabular}{|l|c|}
\hline \multicolumn{1}{|c|}{ Características da análise de necessidades } & Autores consultados \\
\hline - A análise de necessidades responde à questão central de qualquer curso de & \\
línguas para fins específicos: para que serve o curso? & Hutchinson \& Waters \\
- A análise de necessidades leva à identificação de: (a) necessidades-alvo, ou seja, \\
identificação do que o estudante precisa fazer na situação-alvo em termos \\
linguísticos; (b) necessidades de aprendizagem, ou seja, o que o estudante \\
precisa aprender para atuar na situação-alvo no tocante à linguagem, às \\
habilidades e às estratégias exigidas pela situação. & \\
\hline - A análise de necessidades é fundamental para estabelecer os objetivos de \\
aprendizagem da língua.
\end{tabular}




\begin{tabular}{|c|c|}
\hline $\begin{array}{l}\text { - Com base nas necessidades, torna-se possível: (a) elaborar um curso; } \\
\text { (b) avaliar e/ou produzir um material didático; (c) definir os } \\
\text { processos de ensino-aprendizagem e de avaliação dos estudantes. } \\
\text { - A análise de necessidades permite identificar: (a) informações pessoais } \\
\text { e profissionais dos aprendizes; (b) quais aspectos e como a língua será } \\
\text { utilizada nas situaçôes-alvo; (c) informaçóes sobre o ambiente no qual } \\
\text { o curso será desenvolvido. }\end{array}$ & $\begin{array}{l}\text { Dudley-Evans } \\
\text { e St. John (1998) }\end{array}$ \\
\hline $\begin{array}{l}\text { - A análise de necessidades deve ocorrer constantemente ao longo do curso, ou } \\
\text { seja, no pré-curso e durante o curso (para reorientar o seu planejamento) e após } \\
\text { o curso (para verificar a validade das necessidades identificadas anteriormente). } \\
\text { - A análise de necessidades deve servir para identificar os gêneros a serem } \\
\text { explorados ao longo do curso. }\end{array}$ & Ramos et al. (2004) \\
\hline $\begin{array}{l}\text { - Um dos principais instrumentos de identificação de necessidades é o } \\
\text { questionário de pesquisa, já que é possível a obtenção de informaçôes } \\
\text { relevantes de forma rápida. } \\
\text { - O maior problema da aplicação de questionários é que podem ocorrer } \\
\text { algumas limitações na coleta de informações devido ao uso de perguntas } \\
\text { previamente determinadas. Uma solução para isso é a utilização de } \\
\text { entrevistas estruturadas ou semiestruturadas que permitam esclarecer } \\
\text { alguma questão necessária. } \\
\text { - O autor sugere que o foco dos questionários ou entrevistas seja sobre as tarefas } \\
\text { desempenhadas no trabalho, para que estas sejam as unidades de análise. } \\
\text { - A ênfase na tarefa como unidade de análise permite: (a) descrever os cargos e } \\
\text { identificar os conhecimentos necessários para o trabalhador exercer a sua função e } \\
\text { realizar as suas tarefas adequadamente; (b) expandir a análise de necessidades } \\
\text { para além da simples busca de termos linguísticos ou da identificação de listas } \\
\text { de estruturas linguísticas; (c) identificar necessidades para além dos textos, } \\
\text { permitindo observar a dinâmica dos processos de comunicação; (d) utilizar } \\
\text { a experiência das pessoas atuantes no contexto sob análise, para a obtenção de } \\
\text { informaçóes válidas sobre as tarefas que devem ser executadas; (e) reunir os } \\
\text { resultados obtidos e elaborar um conteúdo programático baseado nas tarefas } \\
\text { específicas que devem ser aprendidas pelos alunos. }\end{array}$ & Long (2005) \\
\hline $\begin{array}{l}\text { - A análise de necessidades permite ao professor definir conteúdos mais } \\
\text { significativos, considerando o conhecimento prévio dos estudantes. Isso } \\
\text { possibilita adequar o nível de linguagem, o léxico e os gêneros de texto a serem } \\
\text { utilizados nas situaçóes específicas para as quais os alunos estão se preparando. } \\
\text { - A análise de necessidades permite que o professor passe a conhecer a área na } \\
\text { qual os seus estudantes vão atuar (ou já atuam), possibilitando-lhe proporcionar } \\
\text { um ensino compatível com a sua realidade acadêmica ou ou profissional. }\end{array}$ & $\begin{array}{c}\text { Cintra \& Passarelli } \\
(2008)\end{array}$ \\
\hline
\end{tabular}

Fonte: Elaborado pela autora.

No levantamento apresentado por Souza (2009), observa-se que, nas décadas de 1970 a 1990, o foco estava voltado à identificação de necessidades linguísticas para atuar nas situaçóes-alvo. A partir dos anos 2000, percebe-se que a análise de necessidades torna-se mais abrangente e passa a incluir a identificação de gêneros (RAMOS et al., 2004; CINTRA; PASSARELLI, 2008) ou a identificação de tarefas e de processos comunicativos com o aproveitamento das experiências reais das pessoas atuantes no contexto a ser analisado (LONG, 2005). 
No caso do levantamento de necessidades voltado à identificação de gêneros de texto, o questionário é o instrumento preferencialmente utilizado pelos pesquisadores. Entretanto, em Long (2005), a proposta de entrevista (estruturada ou semiestruturada), em complementação ou substituição à aplicação de questionários, é apresentada como forma de superar possíveis limitações que estes últimos possam trazer. Não obstante, ressaltamos que o foco de Long (2005) são as tarefas desempenhadas pelos profissionais e não a identificação dos gêneros de texto utilizados para realizá-las.

Para o nosso propósito de direcionar a organização de um material didático com base em gêneros para ELFE, é essencial realizar uma análise de necessidades que identifique os gêneros habitualmente utilizados por um profissional do ramo imobiliário, evitando - desse modo - o seu "pinçamento" por meio da aplicação de questionários.

Assim, na tentativa de ir além das limitações decorrentes da aplicação de questionários, expostas por Long (2005), e, ao mesmo tempo, realizar um levantamento de necessidades que revele os gêneros que fazem parte de um contexto de trabalho profissional, apresentamos a proposta teóricometodológica de Bazerman (2005), como base para a organização metodológica para a nossa análise de necessidades.

\subsection{A análise de necessidades focando a identificação dos gê- neros de texto no contexto de trabalho}

Em busca de uma análise de necessidades que pudesse apresentar o quadro de gêneros que caracteriza o trabalho de um Técnico em Transações Imobiliárias, encontramos em Bazerman (2005) uma forma bastante apropriada de identificar os gêneros que compóem o quadro de atividades desses profissionais. Seus instrumentos conceituais permitem identificar as condições de realização de um trabalho, observar a regularidade com que os textos executam tarefas similares e verificar como algumas "profissões, situações e organizações sociais podem estar associadas a um número limitado de textos" (BAZERMAN, 2005, p.19) dentro de sistemas de atividades.

Sua proposta teórica envolve os conceitos de sistema de atividades, sistema de gêneros e conjunto de gêneros como instrumentos para analisar o modo como as pessoas criam novas realidades de significação, relaçóes e conhecimentos por meio do uso de textos, em determinados sistemas de atividade. Além disso, mesmo que em momento algum o autor utilize o termo análise ou levantamento de necessidades, Bazerman (2005) sugere uma metodologia de 
coleta de dados que permite ao pesquisador "mapear" tais sistemas e observar como o sistema de gêneros e o conjunto de gêneros se organizam em determinado contexto. Desse modo, é possível estabelecer um olhar mais abrangente sobre o trabalho desenvolvido pelos profissionais de um determinado ramo de atividade, compreendendo os gêneros utilizados e/ou produzidos por eles para realizarem os diferentes agires que constituem o seu sistema de atividade laboral.

Para o autor, os fatos sociais são produzidos por meio dos textos. Por sua vez, dentro de um ciclo de textos e atividades sociais compõem-se sistemas organizacionais bem articulados, onde circulam tipos de textos específicos, previsíveis e de fácil compreensão dentro daquela esfera. Deste modo, "temos gêneros altamente tipificados de documentos e estruturas sociais altamente tipificadas nas quais esses documentos criam fatos sociais que afetam as ações, direitos e deveres das pessoas" (BAZERMAN, 2005, p.21). Em cada contexto há ciclos identificáveis de textos e atividades, definidos pelos gêneros característicos de um sistema de atividade, e a compreensão desses gêneros é fundamental para diagnosticar os sistemas de atividades.

Usando as definições de Bazerman (2005), criamos a figura a seguir cujo objetivo é ilustrar como se organiza o sistema de atividades, sendo que GT significa gêneros de textos.

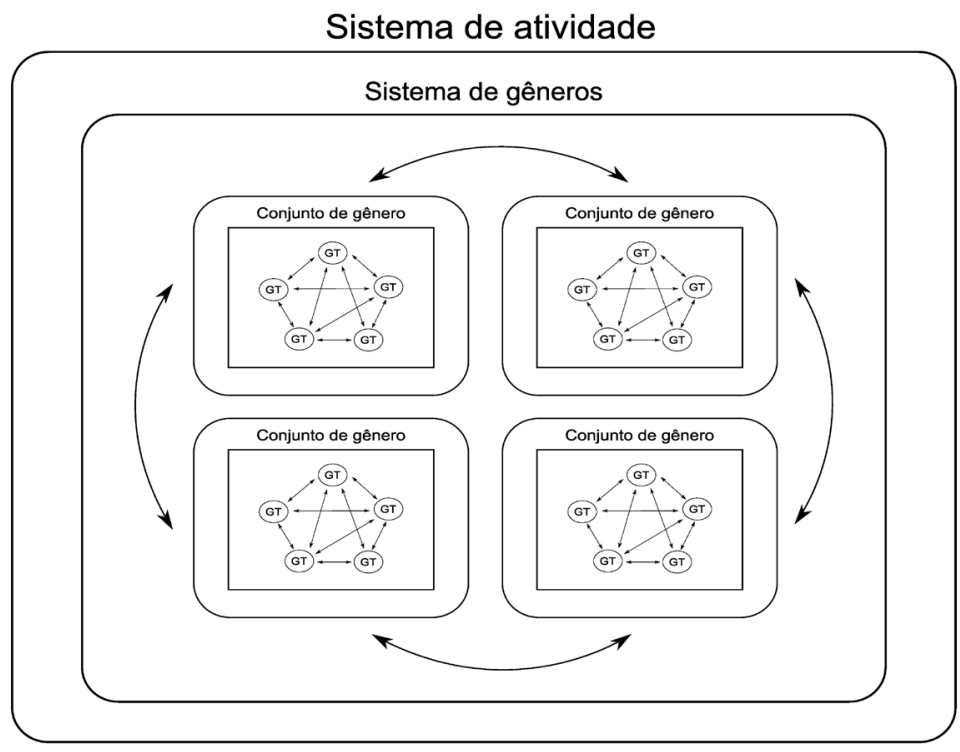

FIGURA 1: Ilustração da organização do sistema de atividades segundo Bazerman (2005). 
Para explicar como os gêneros se configuram e se enquadram em organizações, papéis e atividades mais amplas, e para compreender como se caracterizam, Bazerman (2005, p.32-34) explica que esses sistemas de atividades são compostos por conjuntos de gêneros, ou seja, por uma "coleção de tipos de textos que uma pessoa num determinado papel tende a produzir” (p.32). A catalogação de todos os gêneros que um profissional exerce em seu contexto laboral permite identificar uma parte considerável de seu trabalho. Esse conjunto de gêneros, por sua vez, forma um sistema de gêneros. Em outras palavras, o sistema de gêneros engloba diferentes conjuntos de gêneros utilizados por um coletivo de pessoas que trabalham juntas e de formaorganizada. A sua análise permite: (a) observar as relações padronizadas estabelecidas na produção, circulação e uso desses documentos; (b) capturar "as sequências regulares com que um gênero segue o outro, dentro de um fluxo comunicativo típico de um grupo de pessoas" (p.33). Com isso, "levar em consideração o sistema de atividades junto com o sistema de gêneros é focalizar o que as pessoas fazem e como os textos ajudam as pessoas a fazê-lo, em vez de focalizar os textos como fins em si mesmo" (p.34). Portanto, identificar o sistema de atividades é identificar os agires dos participantes em seu contexto de trabalho.

Relacionando isso com o presente estudo, observar o sistema de atividades que compóe o trabalho de um assessor imobiliário e analisar como sua estrutura se constrói sobre uma infraestrutura de gêneros textuais possibilita perceber como cada texto se encontra e se encaixa nas diferentes atividades sociais ou profissionais, estruturadas naquela organização.

Outro ponto que deriva desse diagnóstico, e com o qual concordamos, é que analisar esses sistemas de atividades é um caminho sólido para ir além de uma observação comum e superficial de um determinado contexto, algo que pode facilmente ocorrer numa análise de necessidades mais focada apenas nas tarefas realizadas ou no "pinçamento" de gêneros por meio de questionários. Muitas vezes, essa estratégia de análise de necessidades não revela a forma como os gêneros são utilizados ou como eles se relacionam uns com os outros dentro do sistema de atividades, dificultando a nossa compreensão referente aos diversos agires concretizados pelos textos pertencentes aos diferentes gêneros, em determinadas situações de trabalho ou estudo.

Essas definições são importantes orientações para direcionar o que deve ser observado em uma análise de necessidades cujo objetivo é identificar os gêneros de texto utilizados pelos profissionais do ramo imobiliário, por exemplo, e entender quais conjuntos de gêneros compõem esse sistema de atividades e, mais especificamente, quais gêneros são utilizados em língua espanhola (na produção e compreensão oral e escrita). 


\section{Procedimentos metodológicos para uma análise de necessi- dades focada na identificação de gêneros de textos utilizados pelo corretor imobiliário}

Realizar uma análise de necessidades em um ambiente ou contexto não familiar ao do pesquisador, como é o caso desta pesquisa voltada ao setor imobiliário, exige os seguintes passos metodológicos (BAZERMAN, 2005, p.42-43): (a) coletar informaçôes sobre os textos e também sobre como as pessoas entendem esses textos, solicitando-lhes que citem os tipos de textos com os quais trabalham, já que isso permite ao pesquisador identificar o conjunto de gêneros; (b) realizar a coleta com mais de uma pessoa, de modo a verificar o grau de concordância entre elas e entender as particularidades do gênero; (c) solicitar, durante a coleta, exemplares dos gêneros mencionados por elas, pois isso permite verificar a similaridade entre eles (incluindo documentos profissionais, legais ou administrativos para entender quais são e como são usados); (d) observar as pessoas ao longo de um determinado tempo (um dia, uma semana, um mês) e anotar em quais ocasiōes os textos são usados e com quais propósitos, além de observar como são produzidos, interpretados e trabalhados; (e) entrevistar as pessoas no momento de uso dos textos, para compreender melhor os significados, intenções, percepções e atividades dos participantes; (f) registrar a sequência em que certos documentos são introduzidos.

Considerando a grande quantidade de itens que devem ser observados, Bazerman (2005, p.44-45) sugere que se delimite e direcione o que realmente se deseja investigar, evitando, a nosso ver, uma coleta de dados demasiadamente ampla e "desnorteada".

Seguindo os passos metodológicos indicados pelo autor e mantendo o foco na identificação dos gêneros que podem compor um material didático de espanhol para um Curso Técnico em Transaçōes Imobiliárias, o próximo quadro apresenta a delimitação de objetivos que norteou a elaboração das questôes para a entrevista. 


\section{QUADRO 2}

Delimitação de objetivos para a elaboração de perguntas

a serem utilizadas durante a entrevista com os assessores imobiliários

Investigação sobre gêneros que circulam no contexto imobiliário

1. Propósitos e delimitaçóes de questôes:

(a) O que nos leva a estar envolvidos nesta análise de necessidades dentro do contexto imobiliário? Identificar os conjuntos de gêneros de texto utilizados no dia a dia do contexto imobiliário e mais especificamente em língua espanhola, entendendo quais são produzidos (oralmente e/ou por escrito) ou lidos pelo corretor imobiliário, foco de formação do curso Técnico em Transaçôes Imobiliárias.

(b) Que perguntas se espera que sejam respondidas com a análise? Dentre os gêneros que compõem os conjuntos de gêneros, quais deles são usados em língua espanhola também? Eles estão associados a outros gêneros em português ou em espanhol? Com que frequência esses gêneros são utilizados em língua espanhola? Há algum que seja mais utilizado que outro?

2. Definição do corpus: identificar os textos ou coleções específicas que se deseja examinar.

(a) Quais textos dentro do conjunto de textos precisam ser examinados? Os gêneros de texto utilizados em língua espanhola no contexto imobiliário, com um foco mais específico naqueles utilizados pelo corretor.

(b) Como obter/adicionar exemplares dos gêneros que precisam ser examinados (para ter uma margem de segurança)? Durante as entrevistas, tentar obter exemplares disponíveis na própria imobiliária ou nos escritórios de assessoria imobiliária, ou solicitar que os entrevistados informem em que suporte eles são/ estão publicados ou em que momentos eles são produzidos (para coleta posterior).

3. Quais ferramentas analíticas serão utilizadas para examinar as consistências e as variaçóes das características e funçóes ou relaçóes na coleção, de modo a evidenciar os padróes relativamente estáveis de textos e atividades? Serão utilizadas as ferramentas de análise e propostas de didatização do interacionismo sociodiscursivo.

Fonte: Elaborado pela autora.

Após a elaboração das perguntas para o roteiro de entrevistas (ANEXO 1), optou-se por realizar entrevistas semiestruturadas, já que elas permitem expandir as respostas em caso de necessidade ou dúvida por parte do entrevistador. As questôes objetivaram compreender quais gêneros (orais e escritos) circulam no contexto laboral das imobiliárias, para que servem, quando são usados e com qual função.

$\mathrm{O}$ roteiro foi dividido em dois momentos. As perguntas da primeira parte tinham como meta a obtenção de um panorama mais geral do trabalho do corretor ou assessor imobiliário, permitindo a identificação dos conjuntos de gêneros produzidos por esses profissionais. A segunda parte da entrevista tinha como objetivo identificar situaçōes, dentre aquelas apontadas na primeira parte, em que o profissional poderia precisar utilizar a língua espanhola. 
Foram entrevistados quatro assessores imobiliários nos três primeiros trimestres de 2013, cuja experiência no mercado de trabalho variou entre 2 a 33 anos. Todas as entrevistas foram realizadas no escritório de assessoria imobiliária dos profissionais e não propriamente em imobiliárias. ${ }^{7}$

\section{Apresentação e discussão dos resultados}

Devido à organização do roteiro de perguntas, os dados coletados nas entrevistas geraram dois grupos de informaçōes. O primeiro refere-se aos conjuntos de gêneros que constituem o contexto laboral geral do corretor em língua portuguesa, o que levou à identificação dos gêneros recebidos ou produzidos em seu cotidiano (a ser apresentado no Quadro 3). O segundo grupo tem relação mais específica com o uso do espanhol no contexto imobiliário, objetivando identificar dentro de cada conjunto de gêneros quais são os gêneros utilizados nessa língua, em que situações e com qual objetivo comunicativo (apresentado no Quadro 4).

O primeiro a destacar é que o trabalho do corretor exige diferentes ações que organizam as diversas situações laborais, formando, portanto, diferentes conjuntos de gêneros: 1 . ações para agenciar imóveis; 2 . açôes para procurar ou atrair clientes em potencial; 3. açôes para persuadir e conhecer melhor o cliente; 4 . ações para concretizar a venda ou locação do imóvel; 5. açōes para manter-se constantemente atualizado.

O Quadro 3 apresenta os gêneros de texto que formam os diferentes conjuntos do sistema de gêneros, bem como a função de cada um deles.

\footnotetext{
${ }^{7}$ No início da pesquisa, a proposta era acessar as principais imobiliárias da cidade de Porto Alegre. Contudo, após as primeiras conversas com os coordenadores dos cursos de Técnico em Transações Imobiliárias, as indicaçōes de profissionais para entrevista foram todas direcionadas a assessores imobiliários com escritório próprio. A vantagem dos escritórios de assessorias imobiliárias é que os profissionais têm uma visão bastante ampla das atividades desempenhadas no ramo. Nas imobiliárias, muitas vezes, há segmentação de funções.
} 


\section{QUADRO 3}

Conjuntos de gêneros de texto que formam o sistema de gêneros dos profissionais do ramo imobiliário.

\begin{tabular}{|c|c|c|}
\hline \begin{tabular}{|l|l} 
Conjunto \\
de gêneros
\end{tabular} & Açōes & Gêneros de textos que formam cada conjunto de gêneros \\
\hline $\begin{array}{l}\text { Conjunto } \\
\text { de gêneros } \\
\text { A }\end{array}$ & $\begin{array}{l}\text { Agenciar imóveis } \\
\text { para criar o seu } \\
\text { catálogo de imóveis }\end{array}$ & $\begin{array}{l}\text { - Anúncios de seus serviços publicados na mídia impressa e virtual. Função: } \\
\text { atrair clientes que desejem colocar o seu imóvel à venda ou para locação. } \\
\text { - Ficha de agenciamento. Função: registrar a situação física dos } \\
\text { imóveis, as condições de venda propostas pelo proprietário, os dados } \\
\text { do vendedor e a descrição total do imóvel. Esse é um documento } \\
\text { essencial para concretizar o agenciamento. Seu preenchimento pode } \\
\text { ser feito por meio de uma ficha impressa ou um formulário virtual. } \\
\text { - Matrícula do imóvel. Função: permitir a obtenção de um "retrato } \\
\text { escrito" do imóvel, revelando antigos e atuais proprietários, possível } \\
\text { alienação ou penhora, outras dívidas pendentes. Isso garante ao } \\
\text { corretor agenciar um imóvel livre de problemas. } \\
\text { - Certidôes negativas. Função: obter informaçães a respeito do } \\
\text { proprietário referente a açôes civis estaduais e federais, açōes } \\
\text { trabalhistas, dívidas de impostos, situação perante a receita fazendária, } \\
\text { possíveis dívidas de IPTU, de condomínio, entre outros. }\end{array}$ \\
\hline $\begin{array}{c}\text { Conjunto } \\
\text { de gêneros } \\
\text { B }\end{array}$ & $\begin{array}{l}\text { Procurar e/ou } \\
\text { atrair clientes } \\
\text { e formar um } \\
\text { banco de dados }\end{array}$ & $\begin{array}{l}\text { - Anúncios de seus serviços publicados na mídia impressa e virtual. } \\
\text { Função: divulgar imóveis para venda ou locação. } \\
\text { - Placas. Função: identificar os imóveis à venda ou para locação } \\
\text { associando-o ao nome da imobiliária. } \\
\text { - Chat. Função: esclarecer dúvidas, estabelecer uma relaçãa com o } \\
\text { cliente e obter o seu contato. }\end{array}$ \\
\hline $\begin{array}{c}\text { Conjunto } \\
\text { de gêneros } \\
\text { C }\end{array}$ & Ofertar imóveis & $\begin{array}{l}\text { - Entrevista. Função: estabelecer uma interação entre o corretor e o } \\
\text { cliente de modo a criar vínculos, traçar o perfil pessoal e financeiro } \\
\text { do cliente, permitindo ao corretor oferecer-lhe um imóvel condizente } \\
\text { com suas necessidades. } \\
\text { - Apresentação de imóveis. Função: traduzir para a realidade o que o } \\
\text { cliente viu no site da imobiliária, analisar se o cliente gostou do } \\
\text { imóvel e de sua localização, tentar solucionar a necessidade apresentada } \\
\text { pelo cliente ampliando a possibilidade de venda ou locação. } \\
\text { - E-mail. Função: tirar dúvidas dos clientes relativas ao imóvel ou à } \\
\text { região onde está localizado, esclarecer as condiçôes de pagamento, } \\
\text { obter dados e identificar seus interesses. } \\
\text { - Apresentação de plantas. Função: apresentar um imóvel que só existe } \\
\text { na planta, auxiliando o cliente a pensar se o tamanho do apartamento e } \\
\text { dos cômodos é adequado (noção de escala), se a metragem é adequada, } \\
\text { como será a área de lazer, entre outros. }\end{array}$ \\
\hline $\begin{array}{l}\text { Conjunto } \\
\text { de gêneros } \\
\text { D }\end{array}$ & $\begin{array}{c}\text { Concretizar a } \\
\text { venda ou locação }\end{array}$ & $\begin{array}{l}\text { - Proposta ou promessa de compra e venda (antigo arras). } \\
\text { Função: estabelecer um contato direto entre comprador e vendedor, } \\
\text { realizando a negociação dos valores e formas de pagamento entre as partes. } \\
\text { - Contrato de compra e venda. Função: tornar legal a transação imobiliária. } \\
\text { - Escritura. Função: concretizar a transferência do imóvel. } \\
\text { - Certidoes negativas. Função: no momento de se efetivar o fechamento de } \\
\text { um negócio, servem para obter informaçōes sobre (a) o comprador (saber } \\
\text { se ele tem condiçōes de adquirir o imóvel) e (b) o vendedor (detectar } \\
\text { se há algum problema com o imóvel que possa prejudicar o comprador). } \\
\text { - E-mail. Função: tirar dúvidas do cliente durante o processo de compra } \\
\text { e venda, solicitar documentos, informar previsões de entrega do } \\
\text { imóvel, entre outros. }\end{array}$ \\
\hline
\end{tabular}




\begin{tabular}{|c|c|c|}
\hline $\begin{array}{c}\text { Conjunto } \\
\text { de gêneros } \\
\text { E }\end{array}$ & $\begin{array}{c}\text { Manter-se } \\
\text { constantemente } \\
\text { atualizado para ser } \\
\text { efetivo e produtivo } \\
\text { em sua atividade }\end{array}$ & $\begin{array}{l}\text { - Publicaçôes de lançamento e pré-lançamento. Função: ficar a par das } \\
\text { - Reportizçages do mercado, conhecer o concorrente, agencias da área de economis imóveis. } \\
\text { tendências do mercado para poder orientar seus clientes e aprofundar } \\
\text { constantemente os seus conhecimentos sobre o assunto. } \\
\text { - Índices da construção civil. Função: ter condiçôes de avaliar um } \\
\text { imóvel dentro do valor de mercado. } \\
\text { - Anúncios de outras imobiliárias. Função: conhecer o concorrente, } \\
\text { agenciar mais imóveis e captar clientes. }\end{array}$ \\
\hline
\end{tabular}

Fonte: Elaborado pela autora.

Percebemos que o sistema de gêneros é formado por cinco conjuntos inter-relacionados de gêneros, contudo, os dados revelaram uma ordem hierárquica entre esses conjuntos. De modo mais detalhado, isso significa que esse sistema de atividades, embora apresente um esquema de conhecimentos prototípicos, funciona com uma lógica organizacional bastante precisa, como podemos verificar em função da análise realizada e apresentada no Quadro 3:

(1) com o objetivo central de vender ou locar imóveis, o primeiro passo é ter imóveis para oferecer. Para tal, o assessor imobiliário precisa utilizar os gêneros descritos no Conjunto de gêneros $A$, essenciais para a ação de agenciar imóveis;

(2) depois, já dispondo de imóveis em seu catálogo para serem ofertados, o corretor precisa encontrar formas de procurar ou atrair clientes em potencial, ação realizada por meio dos gêneros descritos no Conjunto de gêneros B;

(3) após estabelecer contato com os clientes, chega a etapa de ofertar imóveis que interessem ao potencial comprador ou locatário e, para isso, o corretor precisa recorrer aos gêneros característicos do Conjunto de gêneros $C$;

(4) quando, finalmente, o corretor consegue efetivar uma proposta de compra ou locação, a transação imobiliária só se efetiva se todos os documentos relativos a ela forem conhecidos pelo profissional, gêneros característicos do Conjunto de gêneros D.

Para realizar com êxito as ações dos conjuntos de gêneros de A a D, é fundamental que o assessor imobiliário mantenha-se o mais atualizado possível com relação a índices econômicos, índices da construção civil, bem como esteja atento à concorrência e às novas oportunidades do mercado (novos lançamentos e empreendimentos), todos gêneros que caracterizam o Conjunto de gêneros E. Com isso, é possível observar que um corretor não 
pode desenvolver as ações relativas ao conjunto B (procurar clientes), por exemplo, se antes não houver realizado a captação de imóveis, atividade desenvolvida no Conjunto de gêneros $A$ e assim sucessivamente até o conjunto D. A exceção é o Conjunto de gêneros $E$, cuja atividade de atualização do corretor é fundamental para qualificar e obter êxito nas ações relacionadas aos demais conjuntos. Um corretor não desenvolverá adequadamente o seu trabalho, caso não saiba agir em cada situação. Para isso, ele precisa utilizar gêneros orais e/ou escritos variados, sendo que em alguns momentos ele precisará lê-los, em outros escrevê-los e em outros utilizá-los oralmente, sempre com funções comunicativas muito precisas.

Diante desse panorama geral proporcionado pela análise do sistema de atividade, observar e identificar quais gêneros são utilizados em língua espanhola dentro desse sistema permite-nos avaliar quais deles são mais relevantes para serem incluídos na organização de um material didático para ELFE em língua espanhola. Com essa visão mais ampla, torna-se mais fácil entender o papel que os gêneros utilizados também em língua espanhola cumprem no sistema de atividades do ramo imobiliário. Com isso, entendemos que um professor de espanhol de um curso Técnico em Transações Imobiliárias é capaz de definir conteúdos a partir das características de cada gênero, tendo clareza a respeito do tipo de ação que é realizada por meio dos textos.

Assim, o Quadro 4 demonstra de forma sistematizada os gêneros em espanhol identificados na coleta de dados, inserindo-os no sistema de atividade recém-apresentado.

\section{QUADRO 4}

Gêneros de textos em língua espanhola, destacados como relevantes pelos entrevistados

\begin{tabular}{|c|c|c|}
\hline $\begin{array}{c}\text { Conjunto } \\
\text { de gêneros }\end{array}$ & Açóes & $\begin{array}{c}\text { Gêneros de textos em espanhol apontados pelos entrevistados como } \\
\text { necessários para desempenhar adequadamente o seu trabalho }\end{array}$ \\
\hline $\begin{array}{c}\text { Conjunto } \\
\text { de gêneros } \\
\text { A }\end{array}$ & $\begin{array}{c}\text { Agenciar imóveis } \\
\text { para criar o seu } \\
\text { catálogo de imóveis }\end{array}$ & $\begin{array}{c}\text { - Ficha de agenciamento. Necessidade comunicativa: ter uma ficha de } \\
\text { de agenciamento em espanhol e dominar o vocabulário para poder } \\
\text { fazer as perguntas necessárias para seu preenchimento. }\end{array}$ \\
\hline $\begin{array}{c}\text { Conjunto } \\
\text { de gêneros } \\
\text { B }\end{array}$ & $\begin{array}{c}\text { Procurar ou atrair } \\
\text { clientes e formar um } \\
\text { banco de dados }\end{array}$ & $\begin{array}{c}\text { Anúncios } \text { de seus serviços publicados na mídia impressa e virtual. } \\
\text { Necessidade comunicativa: divulgar imóveis para venda ou para locação. } \\
\text { Chat } \text { Necessidade comunicativa: esclarecer dúvidas, estabelecer uma } \\
\text { relaçáo com o cliente e obter o seu contato. }\end{array}$ \\
\hline
\end{tabular}




\begin{tabular}{|c|c|c|}
\hline $\begin{array}{l}\text { Conjunto } \\
\text { de gêneros } \\
\text { C }\end{array}$ & Ofertar imóveis & $\begin{array}{l}\text { - Entrevista. Necessidade comunicativa: ter condiçōes de realizar uma } \\
\text { entrevista em língua espanhola para estabelecer uma interação entre } \\
\text { corretor e cliente, de modo a criar vínculos, atrair o cliente, mostrar } \\
\text { um bom atendimento e traçar o seu perfil pessoal e financeiro para a } \\
\text { oferta de um imóvel adequado. } \\
\text { - Apresentação de imóveis e das características da região onde se localiza. } \\
\text { Necessidade comunicativa: poder apresentar o imóvel de modo a tornar } \\
\text { mais concreta a possibilidade de venda ou locação. } \\
\text { - E-mail. Necessidade comunicativa: efetuar reservas, acertar pagamentos } \\
\text { e tirar dúvidas de clientes a respeito do imóvel, em caso de locação. No } \\
\text { caso de transaçôes de compra e venda, apresentar mais detalhes do imóvel } \\
\text { (quando solicitado) ou tirar dúvidas a respeito da documentação. } \\
\text { - Apresentação de plantas. Necessidade comunicativa: apresentar um } \\
\text { imóvel que só existe na planta. }\end{array}$ \\
\hline $\begin{array}{l}\text { Conjunto } \\
\text { de gêneros } \\
\text { D }\end{array}$ & $\begin{array}{c}\text { Concretizar a } \\
\text { venda ou locação }\end{array}$ & $\begin{array}{l}\text { - Proposta ou promessa de compra e venda (antigo arras). Necessidade } \\
\text { comunicativa: esclarecer alguma dúvida que o cliente possa ter com } \\
\text { algum termo técnico ou jurídico. Estabelecer um contato direto entre } \\
\text { comprador e vendedor, realizando a negociação dos valores e formas de } \\
\text { pagamento entre as partes. } \\
\text { - Contrato de compra, venda ou locação. Necessidade comunicativa: } \\
\text { explicar termos e cláusulas contratuais que o cliente não entenda. } \\
\text { - Carta fiança, carta de recomendação, carta garantia (para locação). } \\
\text { Necessidade comunicativa: ler e compreender o documento. } \\
\text { - Agendamento de vistorias elou assinatura de contratos em cartório. } \\
\text { Necessidade comunicativa: agendar vistorias e/ou marcar horário para } \\
\text { assinatura de contratos em cartório. } \\
\text { - Ficha de vistoria. Necessidade comunicativa: realizar seu preenchimento } \\
\text { e esclarecer possíveis dúvidas do cliente, antes ou após a locação, e } \\
\text { comunicar o resultado da vistoria após a entrega do imóvel. }\end{array}$ \\
\hline $\begin{array}{l}\text { Conjunto } \\
\text { de gêneros } \\
\text { E }\end{array}$ & $\begin{array}{c}\text { Manter-se } \\
\text { constantemente } \\
\text { atualizado para } \\
\text { ser efetivo e } \\
\text { produtivo em } \\
\text { sua atividade }\end{array}$ & $\begin{array}{l}\text { - Ler textos diversos para conhecer o mercado imobiliário e os processos } \\
\text { de transaçôes imobiliárias dos países hispano-falantes (sistema registral, } \\
\text { notarial, documentos necessários nas transaçóes, impostos envolvidos). }\end{array}$ \\
\hline
\end{tabular}

Fonte: Elaborado pela autora.

Diferentemente do observado no Quadro 3, no quadro recémapresentado deixamos de mencionar a função do gênero e passamos a mencionar a necessidade comunicativa expressa pelos entrevistados. Isso ocorreu de forma espontânea durante as entrevistas, pois, ao revelarem que boa parte dos corretores não domina a língua espanhola, os informantes passaram a dizer em quais situaçôes seria fundamental saber utilizá-la. As necessidades comunicativas indicaram gêneros pertencentes aos conjuntos de gêneros apresentados no Quadro 3, porém, surgiram outros novos que não haviam sido mencionados antes, tais como a leitura e compreensão de novos documentos (cartas de fiança, carta de recomendação e carta de garantia), o agendamento de vistoria e a ficha de vistoria. Todos esses gêneros estão 
relacionados com a locação comum e a locação por temporada para estrangeiros falantes de espanhol.

Ainda destacamos que, com base na análise anterior do sistema de atividade, há subsídios para definir quais - dentre os gêneros de textos utilizados em língua espanhola - são mais relevantes durante a transação imobiliária e por quê. Conforme os dados das entrevistas, os gêneros que se enquadram no conjunto $\mathrm{Ce} \mathrm{D}$ mereceriam bastante atenção na definição de conteúdos para um material didático. Chama a atenção que parte significativa dos gêneros destacados nesses conjuntos são gêneros orais (entrevista, apresentação de imóveis, apresentação de plantas, explicação de termos jurídicos ou de cláusulas de contratos de compra e/ou locação, explicação de dúvidas diante de uma ficha de vistoria), o que fornece um direcionamento importante sobre a relevância de enfatizar a produção oral no momento de selecionar gêneros e organizar o material didático. Sobre o gênero entrevista, por exemplo, nas palavras de um dos entrevistados, esse é um "ponto nevrálgico" de uma transação imobiliária: "Quando um cliente tem interesse em comprar um imóvel, é fundamental fazer uma entrevista qualificada com a pessoa. É muito problemático não saber fazer uma pergunta em espanhol.”

Além dos gêneros "nevrálgicos" para efetivar a transação imobiliária, o material didático pode e deve incluir os outros gêneros em sua organização. Porém, compreende-se que isso deva ser definido de acordo com a carga horária disponível para o curso e com a complexidade de cada gênero, sempre conforme as informações que a análise do sistema de atividades revelou.

\section{Algumas considerações}

A análise de necessidades em torno a gêneros de texto, por meio da análise do sistema de atividades proposto por Bazerman (2005), demonstrou ser um percurso válido para a seleção e compreensão das funções comunicativas dos gêneros que podem compor um material didático para ELFE, desde a sua concepção. Compreender o sistema de atividades dos trabalhadores do ramo imobiliário, por meio da identificação de seu sistema de gêneros e de seus conjuntos de gêneros, permite ao professor/pesquisador em ELFE ir além de uma seleção isolada de gêneros ("pinçamento" de gêneros) ou de focar apenas nas tarefas desempenhadas por esses profissionais.

Com essa visão ampla dos conjuntos de gêneros que compõem o sistema de atividade do corretor, o olhar para os gêneros utilizados em língua espanhola por esses profissionais é mais completo e abrangente. O professor 
e/ou elaborador de material didático para ELFE passa a ter condições de compreender como os gêneros utilizados em espanhol se relacionam em cada conjunto e quais ações se realizam por meio deles. Além disso, antes mesmo de tratar das características específicas de cada gênero, é possível entender a sua importância e função dentro de cada conjunto, o que pode auxiliar na definição dos gêneros e, consequentemente, dos conteúdos a serem ensinados.

Conforme revelou a análise do sistema de atividades do contexto imobiliário, há diversos gêneros de texto que podem ser usados em língua espanhola por um corretor, tanto para sua produção oral (entrevistas, apresentação de imóveis, apresentação de plantas, explicação de cláusulas de contratos de compra e venda, agendamento de vistoria) e escrita (ficha de agenciamento, anúncios, chat, e-mail, preenchimento de ficha de vistoria), quanto para a sua recepção, ou seja, leitura de diferentes gêneros relacionados ao mercado imobiliário (carta fiança, carta de recomendação, índices econômicos e da construção civil, notícias e reportagens).

As decisões relativas a quais ensinar devem ser compatíveis com a carga horária disponível para o curso e com a relevância de conhecer este ou aquele gênero no desempenho de sua atividade laboral. De qualquer modo, deve haver coerência na forma como o gênero será explorado didaticamente, para que não se torne apenas um pretexto para o estudo de frases prontas, listas de vocabulário ou de conteúdos gramaticais. Por isso, a futura organização de um material didático em ELFE que se proponha a explorar as capacidades de linguagem que constituem as características de cada gênero identificado, pode levar o estudante a aprender a língua de modo mais contextualizado, preparando-o para utilizar tais textos, em espanhol, em seu futuro contexto laboral.

\section{Referências}

ARANHA, S. A argumentação nas introduçôes de trabalhos científicos da área de química. 1996. 104 f. Dissertação (Mestrado em Linguística Aplicada ao Ensino de Línguas) - Pontifícia Universidade Católica de São Paulo, São Paulo, 1996.

ARAÚJO, A. D. Lexical Signalling: a Study of Unspecific-Nouns in Book Reviews. 1996. 274 f. Tese (Doutorado em Letras - Inglês e Literatura Correspondente) Universidade Federal de Santa Catarina, Florianópolis, 1996.

BAWARSHI, A. S.; REIFF, M. J. Da pesquisa ao ensino: múltiplas abordagens pedagógicas para o ensino de gêneros. In: . Gênero: história, teoria, pesquisa, ensino. São Paulo: Parábola, 2013. p.213-227. 
BAZERMAN, C. Gêneros textuais, tipificação e interação. In: BAZERMAN, C.; DIONÍSIO, A. P.; HOFFNAGEL, J. C. (Org.). Gêneros textuais, tipificação e interação. São Paulo: Cortez, 2005. p.19-46.

BAZERMAN, C. Shaping Written Knowledge: the Genre and Activity of Experimental Article in Science. Madison: The University of Wisconsin Press, 1988. BAZERMAN, C. System of Genres and the Enactment of Social Intentions. In: FREEDMAN, A.; MEDWAY, P. (Org.). Genre and the New Rhetoric. London: Taylor \& Francis, 1994. p.79-101.

BERNARDINO, C. G. Depoimento de alcoólicos anônimos: um estudo do gênero textual. 2000. p.162. Dissertação (Mestrado em Linguística) - Universidade Federal do Ceará, Fortaleza, 2001.

BEZERRA, B. G. A distribuição das informações em resenhas acadêmicas. 2000. $141 \mathrm{f}$. Dissertação (Mestrado em Linguística) - Universidade Federal do Ceará, Fortaleza, 2001.

BHATIA, V. K. Analysing Genre: Language Use in Professional Setting. London: Longman, 1993.

BIASI-RODRIGUES, B. Estratégias de condução de informações em resumos de dissertaçôes. 1998. 2v. Tese (Doutorado em Linguística) - Universidade Federal de Santa Catarina, Florianópolis, 1998.

BRASIL. Lei no 11.892, de 29 de dezembro de 2008. Institui a Rede Federal de Educação Profissional, Científica e Tecnológica, cria os Institutos Federais de Educação, Ciência e Tecnologia e dá outras providências. Diário Oficial da Uniāo, Brasília, 30 dez. 2008, Seção 1, p. 1.

BRINDLEY, G. The role of needs analysis in adult ESL programme design. In: JOHNSON, R.G. (Ed.). The Second Language Curriculum. London: Cambridge University Press, 1989. p.63-68.

BRONCKART, J-P. Atividade de linguagem, discurso e desenvolvimento humano. Organizado por Anna Rachel Machado e Maria de Lourdes Meirelles Matencio. Trad. Anna Rachel Machado, Maria de Lourdes Meirelles Matencio et al. Campinas: Mercado de Letras, 2006.

BRONCKART, J-P. Atividade de linguagem, textos e discursos: por um interacionismo sócio-discursivo. Trad. Anna Raquel Machado, Péricles Cunha. São Paulo: EDUC, 2003.

CARRELAS, D. C. A Tarefa como eixo norteador dos programas de Lingua Espanhola nos cursos técnicos de Turismo e Hotelaria da Escola de Turismo e Hotelaria Canto da Ilha: limites e possibilidades. 2003. 136 f. Dissertação (Mestrado em Turismo e Hotelaria) - Universidade do Vale do Itajaí, Itajaí, 2003. 
CINTRA, A. M. M.; PASSARELLI, L. G. Revisitando o ensino de língua portuguesa para fins específicos. In: CINTRA, A. M. M. (Org.). Ensino de língua portuguesa: reflexão e ação. São Paulo: Educ, 2008. p.60-72.

CRISTOVÃO, V. L. Sequências didáticas para o ensino de línguas. In: DIAS, R.; CRISTOVÃO, V. L. (Org.). O livro didático de língua estrangeira: múltiplas perspectivas. Campinas: Mercado de Letras, 2009. p.305-344.

DOLZ, J.; SCHNEUWLY, B. Les capacités orales de apprenants. In:

(Org.). Pour un enseignement de l'oral: initiation aux genres formels à l'école. Paris: EFS Editéur, 1998. p.75-89.

DUDLEY-EVANS, T.; ST. JOHN, M. J. Developments in English for Specific Purposes: a multi-disciplinary approach. London: Cambridge University Press, 1998.

FREITAS, L. M. A. Espanhol para o turismo: o trabalho dos agentes de viagens. 2005. 156 f. Dissertação (Mestrado em Letras) - Universidade do Estado do Rio de Janeiro, Rio de Janeiro, 2005.

GALVÁN, C. B. Competência comunicativa e competência profissional: espanhol instrumental para hotelaria. 152 f. 2005. Dissertação (Mestrado em Linguística Aplicada e Estudos da Linguagem) - Pontifícia Universidade Católica de São Paulo, São Paulo, 2005.

GREGOLIN, I. V. Ensino de línguas para fins específicos: particularidades do espanhol para negócios em um contexto empresarial brasileiro. 2005. $162 \mathrm{f}$. Dissertação (Mestrado em Estudos Linguísticos) - Universidade Estadual de São Paulo, São José do Rio Preto, 2005.

HEIMAS, B.; BIASI-RODRIGUES, B. A proposta sócio-retórica de John M. Swales para o estudo de gêneros textuais. In: MEURER, J. L; BONINI, Adair; MOTTA-ROTH (Org.). Gêneros: teorias, métodos, debates. São Paulo: Parábola, 2005. p.108-129.

HENDGES, G. R. Novos contextos, novos gêneros: a revisão da seção de literatura em artigos acadêmicos eletrônicos. 2001. 126 f. Dissertação (Mestrado em Letras) - Universidade Federal de Santa Maria, 2001.

HUTCHINSON, T.; WATERS, A. English for Specific Purposes: a learning-centred approach. Cambridge: Cambridge University Press, 1987.

LONG, M. H. Methodological issues in learner needs analysis. In: LONG, M. H. (Ed.). Second Language Needs Analysis. Cambridge: Cambridge University Press, 2005. p.19-76.

MARTIN, J. R. Factual Writing: Exploring and Challenging Social Reality. Geelong: Deakin University Press, 1985. (Republicado: London: OUP, 1989). 
MARTIN, J. R. English Text - Systems and Structure. Philadelphia; Amsterdam: Jonh Benjamins Publishing Company, 1992.

MARTIN, J. R. Grammar Meets Genre: Reflections on the Sydney School. Inaugural Lecture at Sydney University Arts Association, 2000.

MOTTA-ROTH, D. Rethorical Features and Disciplinary Cultures: a Genrebased Study of Academic Book Review in Linguistic, Chemistry and Economics. 1995. 311 f. Tese (Doutorado em Letras - Inglês e Literatura Correspondente) Universidade Federal de Santa Catarina, Florianópolis, 1995.

MOTTA-ROTH, D.; HENDGES, G. R. Uma análise de gênero de resumos acadêmicos (abstracts) em economia, linguística e química. Revista do Centro de Artes e Letras. Santa Maria, v.18, n.1-2, 1996, p.53-90.

RAMOS, R. C. G. Gêneros textuais: uma proposta de aplicação em cursos de inglês para fins específicos. The ESPecialist. São Paulo, v.25, n.2, 2004, p.107-129.

RAMOS, R. C. G. Instrumental no Brasil: a desconstrução de mitos e a construção do futuro. In: FREIRE, Maximina M.; ABRAHÃO, Maria Helena Vieira; BARCELOS, Ana Maria Ferreira. Linguistica Aplicada e Contemporaneidade. Campinas: Pontes Editores, 2005. p.109-123.

RAMOS, R. C. G.; LIMA-LOPES, R. E.; GAZOTTI-VALLIM, M. A. Análise de necessidades: identificando gêneros acadêmicos em um curso de leitura instrumental. The ESPecialist, São Paulo, v.25, n.1, 2004, p.1-29.

SANTOS, M. B. Academic Abstracts: a Genre Analysis. 1995. 110 f. Dissertação (Mestrado em Letras - Inglês e Literatura Correspondente) - Universidade Federal de Santa Catarina, Florianópolis, 1995.

SCHNEUWLY, B. J. Gêneros e tipos de discurso: considerações psicológicas e ontogenéticas In: SCHNEUWLY, B.; DOLZ, J. et al. Gêneros orais e escritos na escola. Trad. e org. Roxane Rojo e Glaís Sales Cordeiro. Campinas: Mercado de Letras, 2004. p.21-39.

SCHNEUWLY, B.; DOLZ, J. Os gêneros escolares: das práticas de linguagem aos objetos de ensino. In: SCHNEUWLY, B.; DOLZ, J. et al. Gêneros orais e escritos na escola. Trad. e org. Roxane Rojo e Glaís Sales Cordeiro. Campinas: Mercado de Letras, 2004. p.71-91.

SILVA, P. M. A Chamada telefônica no ensino-aprendizagem do Espanhol para fins especificos no Curso de Comércio Exterior. 2009. 141 f. Dissertação (Mestrado em Linguística Aplicada) - Universidade de Taubaté, Taubaté, 2009.

SILVA, R. G. A língua espanhola na formação técnica profissional de nivel médio em saúde. 2008. 168 f. Tese (Doutorado em Linguística Aplicada). Universidade Federal Fluminense, Niterói, 2008. 
SOUZA, R. A. Análise de necessidades do uso da lingua inglesa em contexto profissional: área editorial. 2009. 108 f. Dissertação (Mestrado em Linguística Aplicada e Estudos da Linguagem) - Pontifícia Universidade Católica de São Paulo, São Paulo, 2009. STAA, B. V. Elaboração e avaliação de design de curso instrumental on-line de escrita acadêmica em inglês. 2003. 262 f. Tese (Doutorado em Linguística Aplicada e Estudos da Linguagem). Pontifícia Universidade Católica de São Paulo, São Paulo, 2003.

SWALES, J. M. Genre Analysis: English in Academic and Research Settings. Cambridge: CUP, 1990.

VIAN JR., O. O ensino de inglês instrumental para negócios, a linguística sistêmico-funcional e a teoria de gênero/registro. The ESPecialist. São Paulo, v.24, n.1, 2003, p.1-16.

VIAN JR., O. Gêneros discursivos e conhecimento sobre gêneros no planejamento de um curso de português instrumental para ciências contábeis. Linguagem em (Dis) curso, v.6, n.3, 2006, p.389-411.

WEST, R. ESP state of the art. Trabalho apresentado no Simpósio da Associação de Professores de Inglês da Suíça, 1995. 


\section{ANEXO 1}

\section{ROTEIRO DE PERGUNTAS PARA A ENTREVISTA}

Perguntas para entender o contexto laboral do corretor.

1. Há quanto tempo você trabalha como corretor?

2. O que faz exatamente um corretor imobiliário? Quais são os outros cargos dentro de uma imobiliária?

3. Que documentos um corretor precisa conhecer para fazer o seu trabalho (contratos, propostas, etc.)?

4. Que leituras são indispensáveis para o trabalho de um corretor (jornais notícias, reportagens, classificados)?

5. O que você precisa escrever no seu trabalho (propostas, contratos, e-mails, conversas em chats, outros)?

6. Que tipo de coisas é necessário falar, mostrar ou explicar para os seus clientes.

Perguntas para entender o uso do espanhol no dia a dia do contexto imobiliário, objetivando identificar os gêneros.

7. Do que conversamos até agora, em que momentos um corretor pode precisar usar o espanhol?

8. A sua imobiliária atende clientes que falam espanhol?

9. Quais são as nacionalidades mais frequentes?

10. O que esses clientes procuram?

11. O que é necessário mostrar ou explicar para eles?

12. É necessário ler alguma documentação em língua espanhola?

13. É necessário produzir (escrever) alguma documentação em língua espanhola?

14. Quem faz os anúncios de venda e locação de imóveis? Há anúncios em espanhol também? Onde é que eles são publicados?

15. Na época de veraneio, vocês fazem anúncios em espanhol?

16. Um corretor deve saber espanhol para usar em que situações no momento de atender um cliente falante desse idioma?

17. Além do corretor, que outros cargos precisam saber espanhol para atender os clientes? Que tipo de coisa eles precisam saber falar, ler ou entender em espanhol para dar um tratamento adequado ao cliente?

18. Você se lembra de alguma situação curiosa que já aconteceu na imobiliária com alguém que falasse espanhol? Como é que vocês fizeram para se comunicar?

19. Há mais alguma informação no atendimento a um cliente falante de espanhol que você acha importante destacar?

Data de submissão: 29/11/2013. Data de aprovação: 17/04/2014. 
